\title{
Mauremys japonica (Temminck and Schlegel 1835) - Japanese Pond Turtle
}

\author{
Yuichirou Yasukawa ${ }^{1}$, Takashi Yabe $^{2}$, and Hidetoshi OTA ${ }^{3}$ \\ ${ }^{1}$ District Office Okinawa, Takada Reptiles and Wildlife Research Institute, \\ 1-15-3 Teruya, Okinawa City, Okinawa 904-0011, Japan [guau_yasukawa@ybb.ne.jp]; \\ ${ }^{2}$ School of Community Policy, Aichi Gakusen University, \\ 1 Shiotori, Oike-cho, Toyota City, Aichi 471-8532,Japan [yabe@gakusen.ac.jp]; \\ ${ }^{3}$ Tropical Biosphere Research Center, University of the Ryukyus, \\ Nishihara-cho, Okinawa 903-0213, Japan [ota@sci.u-ryukyu.ac.jp]
}

Summary. - The Japanese pond turtle, Mauremys japonica (Family Geoemydidae), is endemic to Japan and is distributed in Honshu, Shikoku, Kyushu, and adjacent small islands. The turtle is found in various freshwater habitats such as swamps, marshes, irrigated rice paddies, ponds, lakes, and rivers. Many of these habitats have been the objects of recent rapid land developments, or under the constant influences of human activities, obviously involving population declines of this species. The overexploitaion by pet dealers and the prevalence of artificially introduced species with similar ecological requirements could be reducing the numbers of this turtle as well. Thus, although the turtle seems still to be relatively abundant in most districts, preservation of its habitats, as well as regulations for the handling of this species and the control of invasive turtles (especially of the red-eared slider Trachemys scripta elegans) should be considered urgently for the conservation of this species. Accumulation of field data for various ecological aspects of the Japanese pond turtle is also strongly desired in order to formulate effective conservation actions.

Distribution. - Japan. Restricted to Honshu, Kyoshu, and Shikoku.

Synonymy. - Emys vulgaris japonica Temminck and Schlegel 1835; Emys japonica; Emys caspica japonica; Clemmys japonica; Mauremys japonica; Ocadia japonica.

SubSPECIES. - None.

STATUS. - IUCN 2007 Red List: Near Threatened (LR/nt) (assessed 2000); CITES: Not Listed.

Taxonomy. - The Japanese pond turtle was first described as Clemmys japonica by Temminck and Schlegel (1835), and then was reassigned to the genus Mauremys together with C. caspica, C. leprosa, and C. mutica by McDowell (1964) when he resurrected the genus. Recent molecular phylogenetic analyses have invariably showed very close affinity of the genus Mauremys, $M$. japonica in particular, with species of the genera Chinemys and Ocadia (Wu et al. 1999; McCord et al. 2000; Honda et al. 2002a; Barth et al. 2004; Sasaki

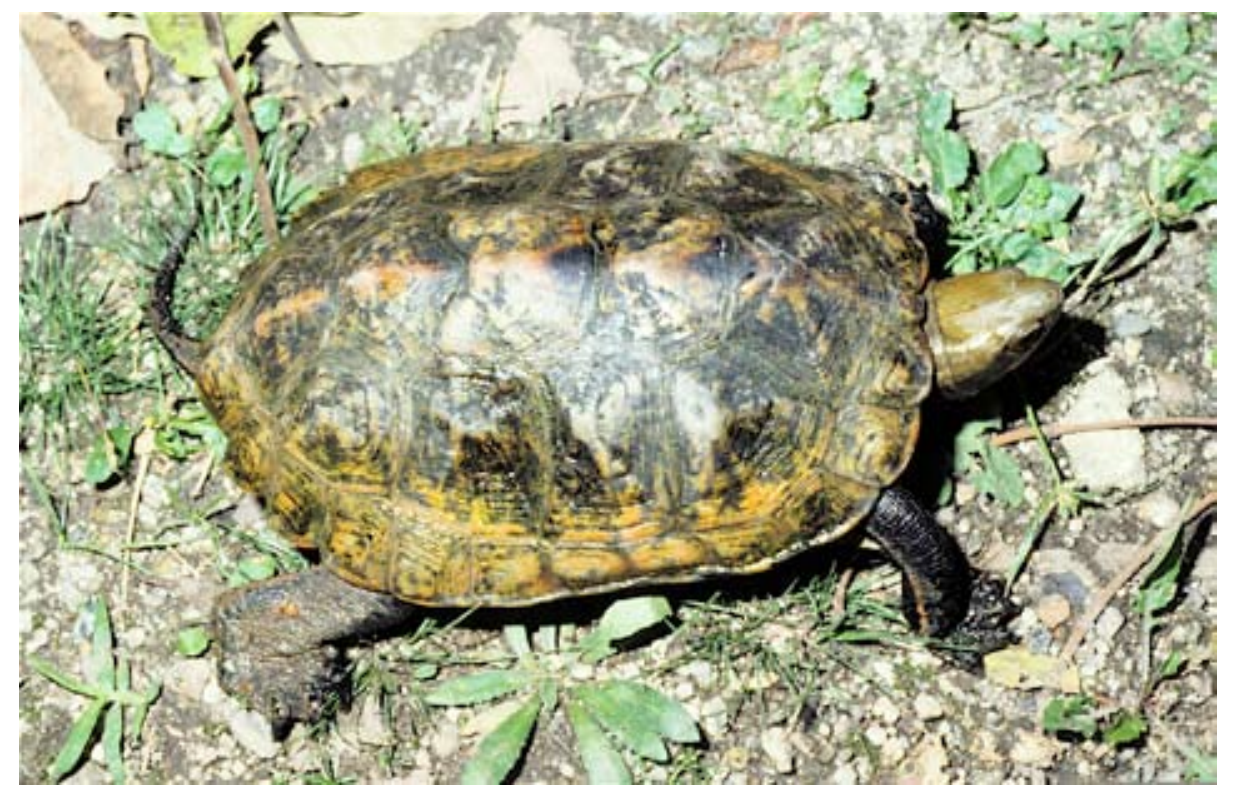

Figure 1. Adult female Mauremys japonica from Shiga, central Honshu, Japan. Photo by Yuichirou Yasukawa. 


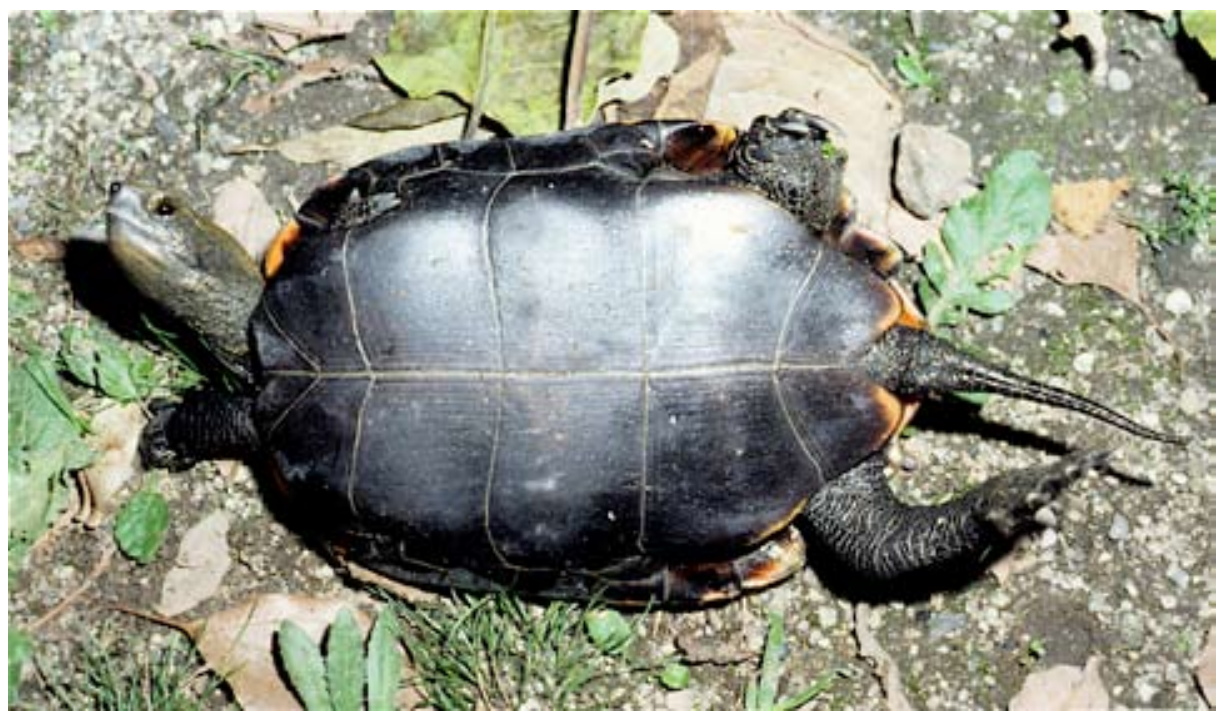

Figure 2. Adult female Mauremys japonica from Shiga, central Honshu, Japan. Photo by Yuichirou Yasukawa.

et al. 2004; Spinks et al. 2004; Feldman and Parham 2004). It is, therefore, clear that the generic arrangement for species currently assigned to the three genera (Mauremys, Chinemys, and Ocadia) needs fundamental revision. Within the Japanese pond turtle, geographic variation is not evident.

Description. - The Japanese pond turtle is a moderate-sized species among the family Geoemydidae, and its carapace length (CL) reaches about $200 \mathrm{~mm}$. The $\mathrm{CL}$ of hatchlings ranges from $30-35 \mathrm{~mm}$. The carapace is oval, relatively depressed, with a low medial keel. The posterior margin of the carapace is strongly serrated in juveniles. The serration becomes weaker with growth, but is still recognizable in adults. The bridge is wide with relatively large axillary and inguinal scutes. The plastron is large, elongate, and hingeless, with shallow anterior and deep posterior notches. The plastral formula is $\mathrm{Ab}><\mathrm{F}$ $><\mathrm{P}>\mathrm{G}><\mathrm{An}><\mathrm{H}$ in most animals. The entoplastron is intersected by gular-humeral and humeral-pectoral seams. The anterior hexagonal neurals are usually broadest anteriorly. The plastral buttresses are well developed, and firmly connected to the carapace. The bony connection

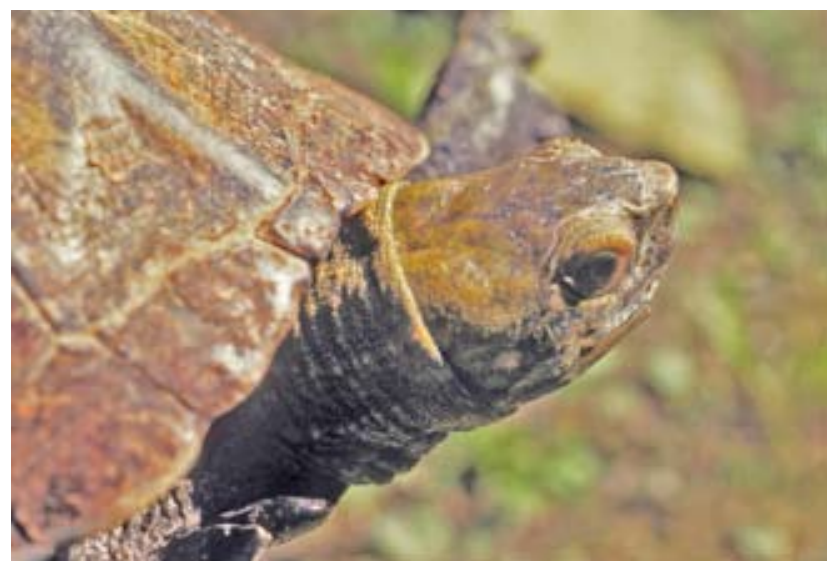

Figure 3. Adult female Mauremys japonica from Kyoto, western Honshu, Japan. Photo by Yuichirou Yasukawa. between the carapace and plastron remains throughout life in both sexes.

The head is relatively small, and its dorsal surface is smooth without small scales. The upper jaw lacks the medial notch or hook. The triturating surfaces of the upper and lower jaws are narrow, without ridges or cusps. Four limbs are sturdy. Digits are fully webbed, bearing well developed claws. There are numerous small conical projections on the base of the tail. Cloacal bursae are well developed.

The skull is relatively depressed and elongate. The bony beak of the upper jaw, formed by the premaxilla, is not hooked or notched. The anterior end of the processus inferior parietalis is usually separated from, but rarely weakly in contact with, the palatine, and always separated from the jugal by the pterygoid. The jugal, postorbital, and quadratejugal contact each other, forming the temporal arch. The postorbital is usually separated from the squamosal by the quadratejugal, but is in contact with the quadrate. The secondary palate is not well developed, and the upper and lower triturating surfaces are narrow, ridgeless, and without serration. The fissure ethmoidalis is narrow and keyholeshaped.

Coloration of the adult carapace is variable, from brilliant orange to dark brown, with a black or dark brown medial stripe. The stripe is occasionally broken into streaks of irregular sizes. Color of connective tissues under the scutes varies from dark brown to greenish gray, forming a fine, complicated flecked pattern. In hatchlings, coloration of the carapace is lighter compared to that in adults, without a dark medial stripe or connective tissue pattern. The plastron and bridges are mostly black, but the outer margin of the former is occasionally partially light-colored. The ground color of the head and neck is similar to, or more grayish than, that of the carapace, with large dark spots on the snout, and between the eye and the tympanum. The ground color of limbs and tail are black or dark gray. A light stripe runs on the outer margin of each limb, and two such stripes on the dorsal surface of the tail. 


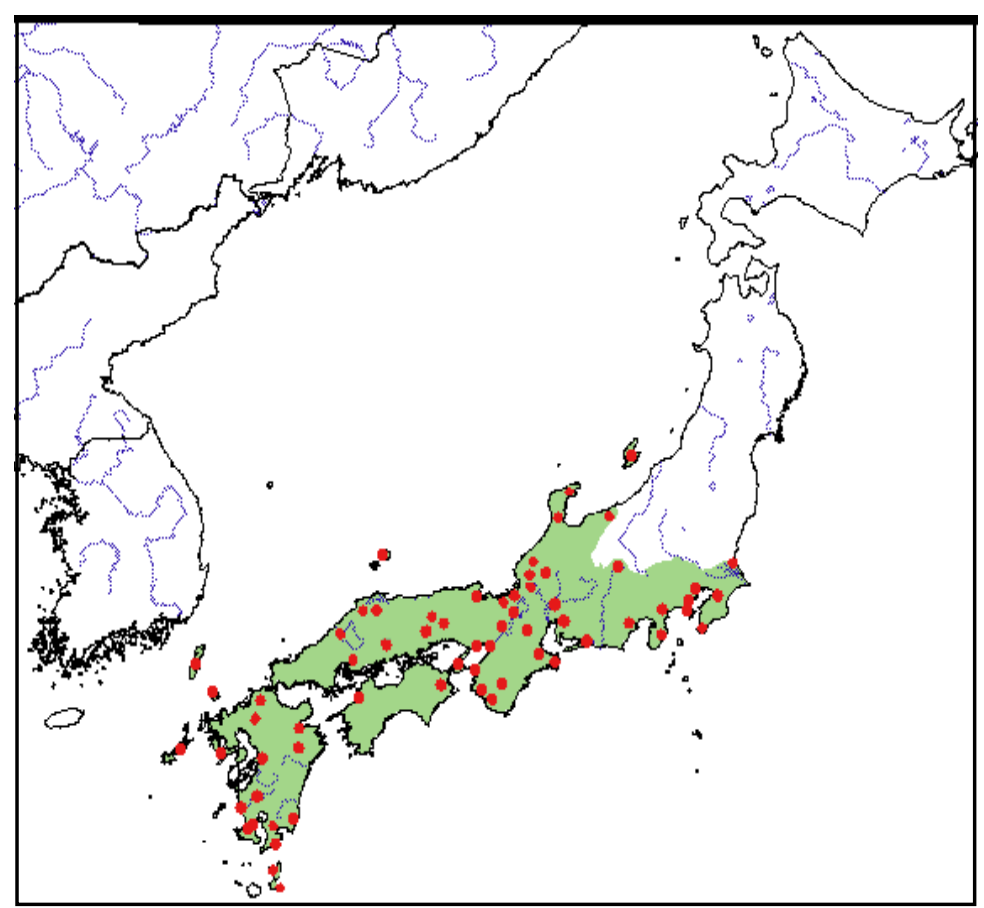

Figure 4. Distribution of Mauremys japonica in Japan. Red points = museum and literature occurrence records based on Iverson (1992) plus more recent and authors' data; green shading = projected distribution based on GIS-defined hydrologic unit compartments (HUCs) constructed around verified localities and then adding HUCs that connect known point localities in the same watershed or physiographic region, and similar habitats and elevations as verified HUCs (Buhlmann et al., unpubl. data), and adjusted based on authors' data.

The Japanese pond turtle shows a remarkable size dimorphism between the sexes: of the specimens examined, the largest female and male reached $201.8 \mathrm{~mm}$ and 145.4 mm CL, respectively (Yabe 1989; Yasukawa, unpubl. data). Males have a relatively low and narrow carapace, short and narrow plastron, and short bridges in comparison with females. Moreover, the plastron is slightly concave in adult males, whereas almost flat or slightly convex in females. The tail of adult males is longer and thicker at the base compared to that of adult females. When the tail is extended backwards, the vent is located far beyond the carapacial rim in males, but on or within the rim in females. However, sexual differences are not evident in immature individuals.

The karyotype is $2 \mathrm{n}=52$ (Nakamura 1935; Sasaki and Itoh 1967; Bickham 1975).

Distribution. - The Japanese pond turtle is endemic to Japan, and is known from Honshu, Shikoku, Kyushu of the main islands, and several small islands adjacent to them (Sadogashima, Awajishima, Okinoshima, Mishima (possibly extinct: see below), Iki jima and Tsushima Islands, and the Goto Group: Ohno 1968; Sengoku 1979; Iverson 1992; Tokumoto and Yano 1998; Matsuo 2005; Yasukawa, pers. obs.). Because the turtle has been popular as a pet animal in Japan, some populations might be non-native, having originated from artificial introductions.

Habitat and Ecology. - Like other species of the genus Mauremys, the Japanese pond turtle is strongly aquatic, spending most of its life time in water. This species seems to be especially adapted to life in deep and flowing waters, and inhabits various freshwater bodies such as upper and middle reaches of rivers, lakes, ponds, swamps, marshes, and irrigated rice paddies. The turtle seems especially abundant in semi-montane environments, although it also occurs on flatlands as well (Yabe 1995, 2002; Kosuge et al. 2003).

The Japanese pond turtle is omnivorous, and feeds on various items such as waterweeds, algae, weed leaves, fallen fruits, earthworms, aquatic and terrestrial snails and insects, crayfish, crabs, shrimp, fish, as well as eggs, larvae, and adults of frogs (Seo 1926; Okada 1950; Yabe 2002; Noda and Kamata 2004; Yabe and Yasukawa, unpubl. data). Feeding has been observed both under and out of water.

Each individual has a well-fixed home range during the summer. With the commencement of the cold season, the turtle migrates to a certain site for overwintering, but remains active even at a water temperature of $5^{\circ} \mathrm{C}$ (Yabe 1992). Preferred sites for overwintering include those under rocks and/or fallen leaves piled on the bottom of a pond or small stream (Yabe 1995). There appear to be high individual fidelities for both summer home ranges and overwintering sites (Yabe 1990).

Recent population studies performed in central Japan yielded data indicating that: the mean CL and body mass in hatchlings are $34 \mathrm{~mm}$ and $8.0 \mathrm{~g}$, respectively; hatchlings gain an average of ca. $28 \mathrm{~mm}$ CL during the first year, and $14 \mathrm{~mm}$ CL during the second year irrespective of its sex, but the growth rate is usually more reduced in males than in females from the third year; mean CL in mature males and females are $104 \mathrm{~mm}$ and $173 \mathrm{~mm}$, respectively; the 
largest male and female measure $145.4 \mathrm{~mm}$ and $201.8 \mathrm{~mm}$ CL, respectively; ca. $17 \%$ of males and $25 \%$ of females seem to be older than 20 yrs (Yabe 1995). Growth rates in another population in a warmer climate were much greater than the above values (Yabe and M. Hasegawa, unpubl. data).

Ishihara (1986) and Yabe (1991) reported that the smallest egg-bearing females they had observed were 150 and $151.8 \mathrm{~mm} \mathrm{CL}$, respectively. On the other hand, males seem to become reproductively mature at approximately $80 \mathrm{~mm}$ CL (Yabe 1992).

Mating season appears to commence in September and extends to April of the next year, with a cessation during the mid-winter period when the water temperature is lower than $9.0^{\circ} \mathrm{C}$ even in the daytime. Copulation occurs under water usually in the following sequence: the male tries to take a position in front of the female; he stretches his forelimbs towards her with his palms directed outwards; he starts waving his forefeet by turns just in front of her head; while continuing the waving, he slowly moves forward to her, or backward when she stretches her neck forward; she becomes motionless, and then, he circles around to her back, and mounts her by clasping the edge of her carapace with the hindlimb claws; intromission then occurs.

The nesting season of the Japanese pond turtle hitherto reported varies considerably among studies as follows: late June to early August (Nagano 1892); usually from early to late June, but rarely in late May (Seo 1926); from April to May (Okada 1950); and from June to early August (Yabe 1991). This inconsistency may reflect geographic variation in this trait. On the other hand, several authors reported the occurrence of multiple clutches during one egg-laying season: usually two but sometimes three (Nagano 1892; Seo 1926; Okada 1950; Yabe 1991). As to clutch size, Ishihara (1986) and Yabe (1991) provided values ranging from 1$12($ mean $=6.7)$ and $2-9($ mean $=6.35)$, respectively. The mean egg size is $36 \times 22 \mathrm{~mm}$ (Yabe 1995). The hatchling emerges from the nest in autumn (Fukada and Ishihara 1976; Yabe 1995).

Little information is available regarding predators of the Japanese pond turtle. Recently, the Japanese striped snake was observed to prey on eggs of this species. Carnivorous mammals such as weasels and dogs sometimes kill even adult turtles (Yabe 1995, 2002).

The Japanese pond turtle is chiefly diurnal, and becomes active during the daytime especially in spring and autumn. But in summer, activity is bimodal, with distinct peaks at dawn and dusk, and less in the daytime, probably as a result of its attempts to avoid the direct sunlight (Ishihara 1981; Yabe 1995; T. Kusano, pers. comm.).

Population Status. - No concrete data are available regarding the nationwide population status of the Japanese pond turtle. But since the turtle is often observed at high densities in various areas, especially in central and western Honshu, there seems to be no fear of immediate extinction. Even so, it is highly likely that many populations have recently been suffering declines (see below).
Threats to Survival. - The greatest threat to the Japanese pond turtle seems to be the reduction or deterioration of habitats caused by land development and various artificial treatments of coasts and bottoms of inland waters. Diversions of rice paddies and agricultural water stocks into housing sites and roads also seem to have been rapidly depriving the turtle, as well as many other freshwater organisms in Japan, of habitats (Kato and Ota 1993), causing constant population declines in a large part of its range.

The Japanese pond turtle seems to be far more vulnerable to artificial changes in habitat condition than the Reeves' turtle, Chinemys reevesii, or the introduced red-eared turtle, Trachemys scripta elegans, both widely occurring sympatrically or parapatrically with the former but supposedly preferring more open habitats and lower reaches of rivers (Yabe 1993; Kosuge et al. 2003; Ota, unpubl. data). Thus, it is highly likely that, in many localities, the above-mentioned human activities are causing the decline or erosion of Japanese pond turtle populations, not only by bringing direct habitat-associated pressures, but also by providing advantages to those potential competitors, which may result in the displacement of M. japonica (Ota, pers. obs.).

In Japan, there is a traditional belief that the turtle is a symbol of good fortune and long life due to its longevity. Thus, quite a few temples, shrines, and parks with ponds on their sites prefer keeping turtles therein. Turtles are also one of the most popular pet animals, and this has caused collection of Japanese pond turtle both by individual and commercial dealers. It is sometimes observed that many turtles gather at a limited suitable site for overwintering. Moreover, the turtles are very easily attracted into traps by bait. Collectors can capture a surprisingly large number of animals in a short period only by detecting such sites (Yabe 1995), and this could cause catastrophic population declines.

Conservation Measures Taken. - A habitat of the Japanese pond turtle and $C$. reevesii on Mishima Island has been designated as a National Natural Monument since 1928 and is protected against any artificial changes by the Japanese Government. However, the Japanese pond turtle has possibly gone extinct there already (causes not specified: Tokumoto and Yano 1998). No other measures have ever been taken for the conservation of this species. In recent editions of the IUCN Red List (Hilton-Taylor 2000; IUCN 2007), the species is rated as Lower Risk/Near Threatened. In 2006 the Japan Ministry of Environment added the Japanese pond turtle to The List of Threatened Wildlife of Japan (i.e., Japanese Red List: Data Deficient category).

Conservation Measures Proposed. - The most effective measures for conservation of the Japanese pond turtle should be the preservation of inland water bodies, especially those located around the border between mountains and flatlands. Regulations for pet-trade activities on the basis of wild-captured animals would be effective as 
well. From a wider viewpoint for the conservation of native freshwater ecosystems, it seems to be urgently necessary to control recently introduced invasive species, including Trachemys scripta.

In order to formulate appropriate conservation actions, it is indispensable to accumulate basic ecological data on this species (such as habitat use, population structure, etc.). To elucidate dynamic aspects of populations (stable or declining), it is also desirable to start long-term monitoring projects on populations in various environments.

Captive Husbandry. - Japanese pond turtles are easy to keep in an aquarium, open cage, or fenced pond, and quite a few experienced keepers have succeeded in the captive breeding of this species (see above for details on mating and egg-laying). The turtle prefers basking, and in order to maintain the animal in a healthy condition, a keeper should consider providing a basking site within the cage. Otherwise, the animal will easily suffer from dermatophilosis (Kamata and Hirose 1998).

Current Research. - Populations of Mie, Gifu, and Chiba Prefectures have recently been studied by Yabe and colleagues using the mark-recapture method.

Acknowledgments. - We thank M. Hasegawa and T. Kusano for generously sharing their unpublished data and observations with us.

\section{LITERATURE CITED}

BICKHAM, J.W. 1975. A cytosystematic study of turtles in the genera Clemmys, Mauremys and Sacalia. Herpetologica 31:198-204.

CITES. 2007. Appendices I, II and III valid from 13 September 2007. www.cites.org/eng/app/index.shtml.

FEldman, C.R. AND PARHAM, J.F. 2004. Molecular systematics of Old World stripe-necked turtles (Testudines: Mauremys). Asiatic Herpetological Research 10:28-37.

FuKADA, H. 1965. Breeding habits of some Japanese reptiles (critical review). Bulletin of Kyoto Gakugei University, Series B 27:65-82.

FuKADA, H. AND IshiHARA, S. 1976. Hatching season of the turtle, Mauremys japonica. Japanese Journal of Herpetology 6(3):9394. (in Japanese)

Hilton-TAYLOR, C. 2000. 2000 IUCN Red List of Threatened Species. Gland and Cambridge: IUCN.

Honda, M., Yasukawa, Y., Hirayama, R., and Ota, H. 2002. Phylogeney of the Eurasian freshwater turtles of the genus Mauremys Gray 1869 (Testudines), with special references to a close affinity of Mauremys japonica with Chinemys reevesii. Journal of Zoological Systematics and Evolutionary Research 40:195-200.

IsHIHARA, S. 1981. A radio-tracking analysis of freshwater turtles. Nature Study 27(3):2-6. (in Japanese)

IsHIHARA, S. 1986. Confirmation of the beginning years of egg laying in the freshwater turtles, Chinemys reevesii and Mauremys japonica. Japanese Journal of Herpetology 11(4):183. (Japanese abstract)

IUCN. 2007. 2007 IUCN Red List of Threatened Species. www. iucnredlist.org.

Iverson, J.B. 1992. A Revised Checklist with Distribution Maps of the Turtles of the World. Richmond, IN: Privately Printed, 363 pp.

Kamata, A. And Hirose, H. 1998. On the dermatophytosis of Mauremys japonica. Aquaculture Science 46(3):377-378. (in
Japanese with English abstract)

Kato, T. AND OTA, H. 1993. Endangered Wildlife of Japan. Osaka: Hoiku-sha, 197 pp. (in Japanese with English summary)

Kosuge, Y., Ogano, H., and Hasegawa, M. 2003. Spatial distribution of the freshwater turtles along Koito River, Boso Peninsula. Journal of the Natural History Museum and Institute, Chiba, Special Issue 6:55-58. (in Japanese with English abstract)

Matsuo,T.2005.Amphibians and Reptiles of Nagasaki Prefecture. Nagasaki: Nagasaki-Shinbunnsha, 155 pp. (in Japanese)

McCord, W.P., Iverson, J.B., SpinKs, P.Q., and Shaffer. H.B. 2000. A new genus of geoemydid turtle from Asia. Hamadryad 25:20-24.

McDowell, S.B. 1964. Partition of the genus Clemmys and related problems in the taxonomy of the aquatic Testudinidae. Proceedings of the Royal Society of London 143:239-279.

Nagano, K. 1899. Experimental studies on egg-laying of freshwater turtles. Dobutsugaku Zasshi 4(49):460-461. (in Japanese)

NAKAmURA, K. 1935. Studies on reptilian chromosomes. VII. Chromosomes of a turtle Clemmys japonica (Temm. and Schl.). Memoirs of the College of Science, Kyoto Imperial University, Series B 10:404-406.

Noda, H. And Kamata, N. 2004. Relationships between population traits and food habits in aquatic turtles. Bulletin of the Herpetological Society of Japan 2004(2):102-113. (in Japanese with English abstract)

OHNo, M. 1968. The herpetological fauna of the islands scattered in the Japan Sea. Journal of the Tokyo University of General Education 9:99-105. (in Japanese with English abstract)

OKADA, Y. 1950. The Order Testudinata. In: Imaizumi, Y., Kuroda, N., and Okada, Y. (Eds.). Animals of Japan. Vol. 1. Vertebrates (1). Osaka: Nihon-Shuppansha, pp. 397-410. (in Japanese)

SASAKI, M. AND ITOH, M. 1967. Preliminary notes on the karyotype of two species of turtles, Clemmys japonica and Geoclemys reevesii. Chromosome Information Service 8:21-22.

Sasaki, T., Takahashi, K., Nikaido, M., Miura, S., Yasukawa, Y., AND OKADA, N. 2004. First application of the SINE (short interspersed repetitive element) method to infer phylogenetic relationships in reptiles: an example from the turtle superfamily Testudinoidea. Molecular Biology and Evolution 21(4):705715 .

Sasaki, T., Yasukawa, Y., Takahashi, K., Miura, S., Shedlock, A.M., AND OKADA, N. 2007. Extensive morphological convergence and rapid radiation in the evolutionary history of the family Geoemydidae (Old World pond turtles) revealed by SINE insertion analysis. Systematic Biology 55(6):912-927.

Sengoku, S. 1979. Ishi-game (Mauremys japonica). In: Sengoku, S. (Ed.). Amphibians and Reptiles in Color. Tokyo: Ieno-Hikari Kyokai, pp. 5. (in Japanese)

SEO, H. 1926. Ishi-game (Mauremys japonica). In: Okazaki, T. (Ed.). Basic Studies of Animals for Teaching Materials. Tokyo: Bunyo-sha, pp. 201-231. (in Japanese)

SPINKS, P.Q., SHAFFER, H.B., IVERSON, J.B., AND MCCORD, W.P. 2004. Phylogenetic hypotheses for the turtle family Geoemydidae. Molecular Phylogenetics and Evolution 32(1):164-182.

Temminck, C.J. and Schlegel, H. 1835. Reptilia. Chelonii. In: de Siebold, Ph. Fr. Fauna Japonica. Amsterdam: Privately Published, pp. 1-80.

ToKumoto, T. And Yano, H. 1998. On freshwater turtles distributed in Mishima Island, Hagi City, Yamaguchi Prefecture. Journal of the Yamaguchi Society of Biology 25:17-24. (in Japanese)

Wu, P., ZHou, K., AND YANG, Q., 1998. Evolution of hinged turtles in Bataguridae inferred from sequences of $12 \mathrm{~S}$ rRNA gene. Chinese Journal of Applied and Environmental Biology 4:374378. (in Chinese with English abstract)

YABE, T. 1989. Population structure and growth of the Japanese pond turtle, Mauremys japonica. Japanese Journal of 
Herpetology 13(1):7-9.

YABE, T. 1990. Home range of the Japanese pond turtle, Mauremys japonica, assessed by radio-tracking method. 5th Internatinal Congress of Ecology. (abstract)

YABE, T. 1991. Reproductive ecology of female Japanese pond turtles, Mauremysjaponica, investigated by X-ray photography. Japanese Journal of Herpetology 14(2):82. (Japanese abstract)

YABE, T. 1992. Sexual difference in annual activity and home range of the Japanese pond turtle, Mauremys japonica, assessed by mark-capture and radio-tracking methods. Japanese Journal of Herpetology 14(4):191-197.

YABE, T. 1993. Effect of the development of two wild ponds on the population of freshwater turtles. Bulletin of Kansai Organization for Nature Conservation 15(1):3-12. (in Japanese)

YABE, T. 1995. Ishi-game (Mauremys japonica). In: Odate, S. (Ed.). Fundamental Data of Rare Aquatic Wildlife in Japan. II (IV). Tokyo: Japan Fisheries Resource Conservation
Association, pp. 455-462. (in Japanese)

YABE, T. 2002. Freshwater turtles of village forests. In: Hiroki, S. (Ed.). Ecology of Village Forests. Nagoya: The University of Nagoya Press, pp. 176-184. (in Japanese)

\section{Citation Format for this Account:}

Yasukawa, Y., Yabe, T. and Ota, H. 2008. Mauremys japonica (Temminck and Schlegel 1835) - Japanese pond turtle. In: Rhodin, A.G.J., Pritchard, P.C.H., van Dijk, P.P., Saumure, R.A., Buhlmann, K.A., and Iverson, J.B. (Eds.). Conservation Biology of Freshwater Turtles and Tortoises: A Compilation Project of the IUCN/SSC Tortoise and Freshwater Turtle Specialist Group. Chelonian Research Monographs No. 5, pp. 003.1-003.6, doi:10.3854/crm.5.003.japonica.v1.2008, http:// www.iucn-tftsg.org/cbftt. 